\title{
Design of arduino-based loading management system to improve continuity of solar power supply
}

\author{
Muhardika, Syafii \\ Department of Electrical Engineering, Universitas Andalas, Indonesia
}

\begin{tabular}{l} 
Article Info \\
\hline Article history: \\
Received Sep 24, 2019 \\
Revised Feb 3, 2020 \\
Accepted May 27, 2020 \\
\hline
\end{tabular}

\section{Keywords:}

Arduino controller

Loading management system

Solar power supply

\begin{abstract}
Solar power plants using environmentally friendly technology in the process of harvesting energy from the sun can be a solution to the future electricity crisis so that it has been the most widely developed and reliable alternative. However, the conversion of solar energy depends on the availability and conditions of sunlight. In sunny conditions, the PV system can serve large loads while charging the battery to the maximum. While in cloudy weather conditions or at night, the PV system serves the load and without charge of the battery. The battery will discharge the stored energy until it runs out, and the supply to the load will be cut off before the desired time. Therefore, research on the PV system loading management system is needed to increase the amount of electricity from solar energy and maintain the continuity of electricity supply to the load. The load power management strategy follows the conditions of sunny, cloudy, rainy, or night time by considering the remaining capacity of the battery that can be used. Load installations are designed to consist of low, medium, and high load installations. Simulation results show that the use of PV loading management strategies can increase the operating time of the PV system. When the remaining less than $10 \%$ battery capacity and PLN supply is available, the supply will be switched to PLN. The remaining $10 \%$ of PV battery capacity could be used to maintain electricity supply to a low load if the PLN supply interrupted. Thus, the use of a loading management strategy will increase the electricity supply from renewable energy and improve the sustainability of electricity supply.
\end{abstract}

Copyright $\odot 2020$ Institute of Advanced Engineering and Science. All rights reserved.

\section{Corresponding Author:}

Syafii,

Electrical Engineering Department, Universitas Andalas,

Padang, Indonesia.

Email: syafii@eng.unand.ac.id

\section{INTRODUCTION}

Indonesia is the largest tropical archipelago country. The number of islands in Indonesia is approximately 17,000 islands [1], with a population of more than 250 million and spread over more than 65,000 regions and islands. One of the essential needs of people's lives is the availability of electricity. Almost all community activities currently depend on electricity, both in-office activities, households, and other activities. The importance of this electrical energy makes electricity consumption increase every year. One effort that can be done to meet these needs is by utilizing a power plant with renewable energy sources such as solar power. Based on the research result in [2], during the clear sky, the potential of a $2 \mathrm{kWp}$ on-grid PV system produced 6,709Wh energy per day in Padang, Sumatera Island area.

The Indonesian government, through regulation No. 79 of 2014, about National energy policy [3] has made solar power plants as a priority renewable energy source that will be developed in Indonesia. The new and renewable energy target of $23 \%$ in 2025 and $31 \%$ in 2050. Generally, solar power plants can be classified into two types according to the component configuration, namely on-grid PV system that is connected to the electricity network (on-grid) and off-grid PV system that stands alone. The main components in the on-grid 
PV system are solar panels and inverters that can sync with the PLN grid. The on-grid system can directly offset the electricity bill. But this system has the disadvantage that if the electricity from the PLN is cut off, then the on-grid PV system will also be disconnected. Likewise, at night the on-grid PV system will automatically off sync, whereas the off-grid PV system can operate independently to supply DC or AC loads. This system is very suitable to be a source of electricity in the region remote areas that are difficult to access by national grid networks [4].

However, the type of off-grid solar power plants is very dependent on the availability of sunlight in charging the battery. When the sun is not available, the charging current the battery will stop, the load will be supplied from the remaining storage system such as batteries. In producing electricity, solar power plants are very dependent on the intensity of solar radiation. The intensity of solar radiation is high when the sunny weather. During sunny weather, per $\mathrm{m}^{2}$ solar panel produces daily average energy conversion higher than 6 $\mathrm{kWh} / \mathrm{m}^{2}$. Whereas when the weather is not clear, the energy produced is not as much when the weather is sunny, i.e., less than $5 \mathrm{kWh} / \mathrm{m}^{2}$ [5]. The uncertainty of the power produced by this photovoltaic can disrupt the continuity of electricity distribution. Therefore, a utility power source is still needed to back up the main supply and ensure the sustainability of the operational process.

The load will be cut off when the remaining battery capacity can be used up. So the issue of increasing the continuity of electricity supply off-grid solar power plants is essential. In off-grid PV systems, the battery capacity must be taken into account the reserve if the weather conditions are unfriendly, which results in less sunlight energy production. The Ministry of Energy and Mineral Resources advises the community that uses this system to use batteries with a minimum reserve capacity of 3 days as a benchmark. This condition will increase battery investment. Thus research is needed to optimize off-grid solar power generation capacity both on the supply side and the demand side.

\section{ARDUINO BASED LOAD MANAGEMENT AUTOMATION SYSTEM}

Increased public awareness of environmental preservation and rising fuel prices have stimulated researchers in the supply sector electric power to continue to expand the generating system environmentally friendly renewable electricity [6]. The location Indonesia is located in the equatorial area theoretically, it will always be exposed to the sun for 10-12 hours a day, and almost all regions of Indonesia get relatively uniform irradiation intensity $[2,7]$. This condition decent enough to be used as an energy source Sun. Solar power generation has also become a priority source of renewable energy that will be developed in Indonesia, and the installation of this plant continues to increase in a variety of areas with renewable energy policy.

The performance of solar panels is very dependent on the sun's rays it receives [8-9]. In sunny conditions, solar panels can serve large loads at once, charging the battery to the maximum. Whereas at cloudy weather conditions or nighttime solar panels do not able to serve the load and charge the battery. The battery will release the stored energy until it runs out, and the supply to the load will be cut off before that time is desirable. Therefore, related research is needed optimization techniques for solar power plants and loading management so that the continuity of electricity supply is maintained following sun availability.

Some previous studies have optimized the Solar Power Plant in various aspects, especially the generation side. Kazem $\mathrm{H}$ has presented a method for designing an optimal capacity Off-grid PV system for remote areas in Sohar-Oman [10]. The proposed model by finding a large right tilt angle on panel installation solar using Matlab simulation. Simulation results have been showing improved system performance. The design of the off-grid PV system for greenhouse applications in the City of Sabha, Libya has been presented in reference [11]. Study results show that the installation of an off-grid PV system can be competing with diesel generators. Optimization technique others for land saving and cost reduction investment in developing PV system [12] and using techniques cooling system on solar panels with a floating system tracker [13] was made. The paper in [14] proposed a new optimal operation of microgrids (MGs) in a distribution system with solar photovoltaic (PV) energy systems and battery energy storage (BES) systems. The active and reactive power flow optimization for PV connected to the grid system using Newton Raphson method has been reported in [15]. This optimization system has increased the reliability and efficiency of the use of solar energy sources.

Research related to optimizing systems utilization of the PV system has been carried out both on the off-grid [16], [11] and on-grid PV systems [17-19]. Several previous studies used the combination of PV with other alternative generators simultaneously to increase the electricity supply from renewable energy generation [20-22]. Utilization optimization techniques of the PV system are mostly done on the supply side, while solar energy conservation opportunities can also be done on the demand side. Therefore on the demand side required loading management system for solar-powered to increase supply continuity follows sun availability. Management strategy planned to load follows the circumstances clear sky weather, cloudy, rain, or night. Installation of the load will be arranged so that there is a load option low, medium, and high load. Next will be the construction of a load management system (LMS) evenly following the time and function automatically 
use an Arduino controller. Thus the available PV batteries storage capacity and conditions charging solar panels remain capable of serving loads for each cycle without termination. System design results and a simulation of how long to use it will be given in the next section of this article.

\section{RESEARCH METHOD}

Research on the management strategy of loading the solar power plant performed on an off-grid solar power plant design model household 900 VA. The off-grid Solar power generation system consists of 4 units of solar panels@250 Wp installed in parallel, 1 unit Luminous 1500 VA inverter, and two units deep cycle batteries. The specifications of the Luminous Solar Inverter [23] are: type pure sine wave, with a rating of 1500 VA, charging time battery to full: 10-12 hours with a charging rating: $40 \mathrm{Amp} / 24 \mathrm{~V}$.

The stages of the study began with the specific test solar power energy conversion and loading. From the results of the characteristics of solar panel, energy conversion tests are obtained charging current curve. Based on the charging current is done development of loading management algorithms. Next is the management system simulation charging off-grid PV system for various weather conditions sunny, cloudy, rainy, and night until it is obtained best performance result.

The design of the management automation system to model the loading of off-grid PV systems such as household scale is shown in Figure 1. The load management automation system follows the time and function automatically using the Arduino microcontroller. Module current and DC voltage sensors are used to obtain charging current and battery terminal voltage. Remaining battery capacity (RBC) can be obtained from Eq (1) the following:

$$
\text { Voc_Bat }=\text { Vt_Bat }+ \text { Iload } x \text { Rin }
$$

Where Voc_Bat is the battery open-circuit voltage, Vt_Bat the battery terminal voltage, Iload is the load current, and Rin is the resistance in the PV system. AC load current (Ib) is obtained from the sensor reading ACS712. Load installation consists of low load installation, medium, and high as Figure 1. As a switch, automatic breakers can be used $220 \mathrm{~V}$ relay driven by an Arduino-controlled $5 \mathrm{~V}$ relay. The simulation of available battery capacity follows the current capability of charging solar panels to serve load for each cycle without termination. Long The usage time of a Power Plant is calculated using Eq (2) the following:

$$
\text { T_Bat=((C_Bat x V)/1000)/(L/1000) }
$$

Where CBat is the battery capacity (Ah), TBat shows the amount of time remaining in the battery capacity, L is load (Watts), and V battery voltage (Volts). This paper will present a strategy simulation load of PV system with a microcontroller (uC) control Arduino to function as an automatic switch Solar Power Plants with PLN and the load management function high, medium, and low.

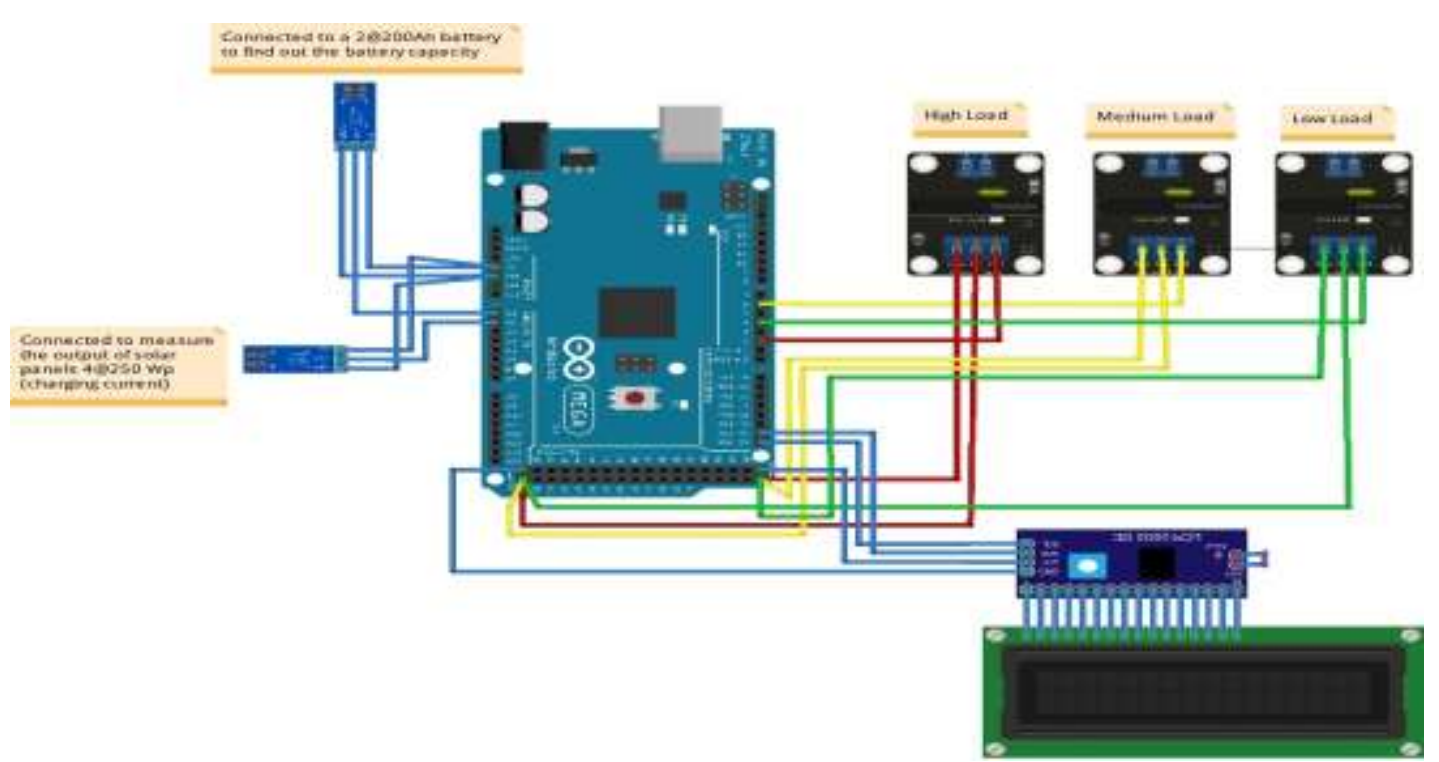

Figure 1. Design of load management system 
In this study, a smart load management automation system was designed that off-grid PV system as the primary source and the State Electricity Company (Perusahaan Listrik Negara, PLN) as a backup source. The PV system storage saves the excess power generated into the battery. By reading the output voltage of the battery, information is obtained about the energy remaining in the battery. The PV battery is connected to the voltage sensor module. The PV battery output voltage will be read by the voltage sensor module, which will be the input for Arduino mega 2560. The voltage that is read by the voltage sensor will be input to Arduino Mega 2560. Where when the battery voltage is less than a certain setting and the source of PLN is available, Arduino will relay the $5 \mathrm{~V}$ relay work to energized $220 \mathrm{~V}$ relay (SSR) is normally open (NO) so that switching occurs automatically. The PLN source supplies the load. However, when the PV battery output voltage that is read by a voltage sensor reaches more than a certain setting, Arduino will interfere with $5 \mathrm{~V}$ relay work to energized $220 \mathrm{~V}$ relay (SSR) to work, so that switching occurs automatically. The PV system resupplies the load.

\section{RESULTS AND ANALYSIS}

The experimental results of measuring the charging panel current solar system installed on the 4th floor of the Department Building Electrical Engineering for four units of $250 \mathrm{Wp}$ solar panels per unit, which are installed parallel, are as shown in Figure 2. Conditions the weather when the data collection is relatively sunny. From the curve, it appears that the charging current has begun to emerge since the morning after six and rises at midday and back down late in the afternoon until 6 p.m. In sunny conditions around 10:00 to at 14.00, the solar panel charging current is quite large so that it can serve large loads at once, charging the battery to the maximum. Nevertheless, the significant charging current can change and is very determined from weather conditions. Charging current fluctuations also occur because of sunlight blocked by clouds despite fine weather.

The DC voltage sensor module is used to obtain a large battery terminal voltage. Resistance Internal averages are used to estimate status battery charging. The remaining battery capacity can be obtained from equation (1), as in Table 1. Based on the solar panel charging current curve and residual battery capacity can be arranged loading patterns. Solar power plants, as shown in Figure 3. During the charging current range relatively large above 20 Amperes, a solar power generation system would be able to serve high loads, under intermediate charging current conditions $10 \mathrm{~A}$ to $20 \mathrm{~A}$, solar power plants are given a medium load.

Meanwhile, if less than $10 \mathrm{~A}$, the loading option low used. These conditions apply all day, like Figure 3. High load operation can be obtained in the time of 10:30 to 1:30 p.m., the medium load starts from 6:30 p.m. until 10:30 and starting at 13:30 until 5:30 p.m., Whereas low load operations for night conditions from 17:30 until 6:30 in the morning.



Figure 2. The charging current curve 




Figure 3. Daily load pattern

Table 1. Simulation of the time of use, charging current, and weather conditions

\begin{tabular}{|c|c|c|c|c|c|c|}
\hline Battery Capacity & $\mathrm{kWh}$ & $\begin{array}{l}\text { Load } \\
\text { (Watt) }\end{array}$ & $\begin{array}{c}\text { Duration } \\
\text { (Hours) }\end{array}$ & $\begin{array}{c}\text { Charging } \\
\text { Current }(\%)\end{array}$ & Weather & $\begin{array}{l}\text { Load Switch } \\
\text { Position }\end{array}$ \\
\hline \multicolumn{7}{|l|}{ Battery Capacity $320 \mathrm{Ah}$} \\
\hline 120 & 2,90 & $750-500$ & 3,89 & 100 & Sunny & High \\
\hline 100 & 2,6 & $500-250$ & 5,0 & 65 & Cloudy & Medium \\
\hline 100 & 2,6 & $<250$ & 10 & 30 & Rainy & Low \\
\hline \multicolumn{7}{|l|}{ Battery Capacity $260 \mathrm{Ah}$} \\
\hline 60 & 1,47 & $750-500$ & 1,98 & 65 & Cloudy & Medium \\
\hline 100 & 2,6 & $500-250$ & 5,0 & 30 & Rainy & Low \\
\hline 100 & 2,6 & $<250$ & 10 & 100 & Sunny & High \\
\hline \multicolumn{7}{|l|}{ Battery Capacity $200 \mathrm{Ah}$} \\
\hline NA & NA & $750-500$ & 0 & 100 & Sunny & High \\
\hline 100 & 2,6 & $500-250$ & 5,0 & 65 & Cloudy & Medium \\
\hline 100 & 2,6 & $<250$ & 10 & 65 & Cloudy & Medium \\
\hline \multicolumn{7}{|l|}{ Battery Capacity $150 \mathrm{Ah}$} \\
\hline NA & NA & $750-500$ & 0 & 100 & Sunny & High \\
\hline 50 & 1,4 & $500-250$ & 2,7 & 100 & Sunny & High \\
\hline 100 & 2,6 & $<250$ & 10 & 65 & Cloudly & Medium \\
\hline \multicolumn{7}{|l|}{ Battery Capacity $100 \mathrm{Ah}$} \\
\hline NA & NA & $750-500$ & 0 & 65 & Cloudy & Medium \\
\hline NA & NA & $500-250$ & 0 & 100 & Sunny & High \\
\hline 100 & 2,6 & $<250$ & 10 & 30 & Rainy & Low \\
\hline
\end{tabular}

The simulation results are shown in Table 1 for three loading types, i.e., low load (250 Watt), moderate (500 Watt), and high (750 Watt). At the time of battery capacity, only $100 \mathrm{Ah}$ is cloudy, or before nightfall days, the load is at a low load status. With low load usage, long operating time Solar Power Plants around 10 hours, still less 1.98 hours without electricity supply from the Solar Power Plants. Therefore, as a backup of electric power, PLN must still be used.

The strategy of loading the solar power plants follows the weather shown in Figure 4. During weather conditions, the clouded charging current will decrease and get smaller when the weather conditions rain. Charging pattern on the condition cloudy weather only operates for load installation low and medium. In contrast, in rainy conditions, Medium load installations will be interrupted and left only lighting loads with a total capacity of 250 Watt. In bright terms, the battery charging current is large sufficient batteries can charge while serving a big load (High).

The design of the control system for loading the Solar Power Plant is expected to work following the remaining battery capacity setting. This system is designed to work to move the switch if the voltage of the Solar Power Plant is less than 65\%. The switch will be switched to a medium load.

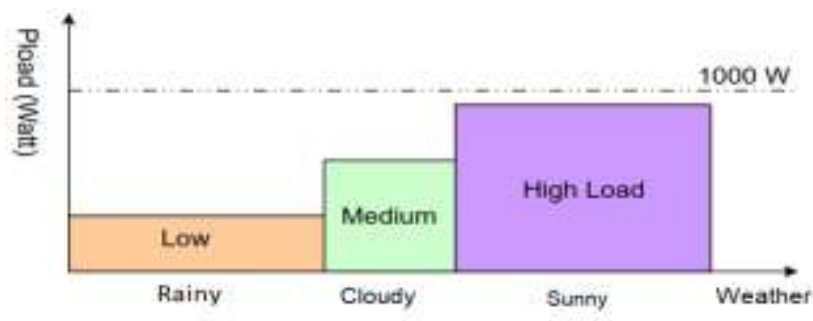

Figure 4. The pattern of load follows the weather during the day 
Meanwhile, when the PV system battery is more than $65 \%$, the switch will return to high load again. Likewise, when the battery capacity is less than $30 \%$, the switch will be transferred to a low load. When the remaining battery capacity is $10 \%$, and PLN is available, the supply switch will be changed to PLN. This condition used to improve reliability as long as the charging current for PV system not yet available. When PLN goes out, the remaining $10 \%$ capacity of the solar battery storage can be used to keep the electricity supply a low load. PLN's average system interruption (SAIDI) duration for 2017 is 14.61 hours/year, and PLN's average system interference (SAIFI) frequency index is 9.69 times/year [24]. On average, the duration of a PLN outage is around two hours / interrupt time, so a 10\% setting of 2 @200Ah battery capacity is sufficient to serve low loads overcoming a PLN outage. Therefore, the Arduino-based generation control system can later increase the electricity supply of solar power plants and improve the continuity of electricity supply.

The loading management system was designed based on PV battery open-circuit voltage and terminal voltage parameters, as shown in Figure 5. When the set point of the LMS setting reach, LMS will be operated to transfer the load supply. Based on the simulation that has been done with several conditions shows that LMS has worked following predetermined settings. If the PV battery voltage is $100 \%$ then it can supply high loads, but if the PV battery is less than $65 \%$ then the load that can be supplied is a medium load, and if the PV battery is less than $30 \%$ then the load that can be supplied is a low load. If the PV battery is less than $10 \%$ and PLN available, LMS transferred to PLN. Where as when the PV battery is more than $10 \%$, LMS switches again to the PV system.

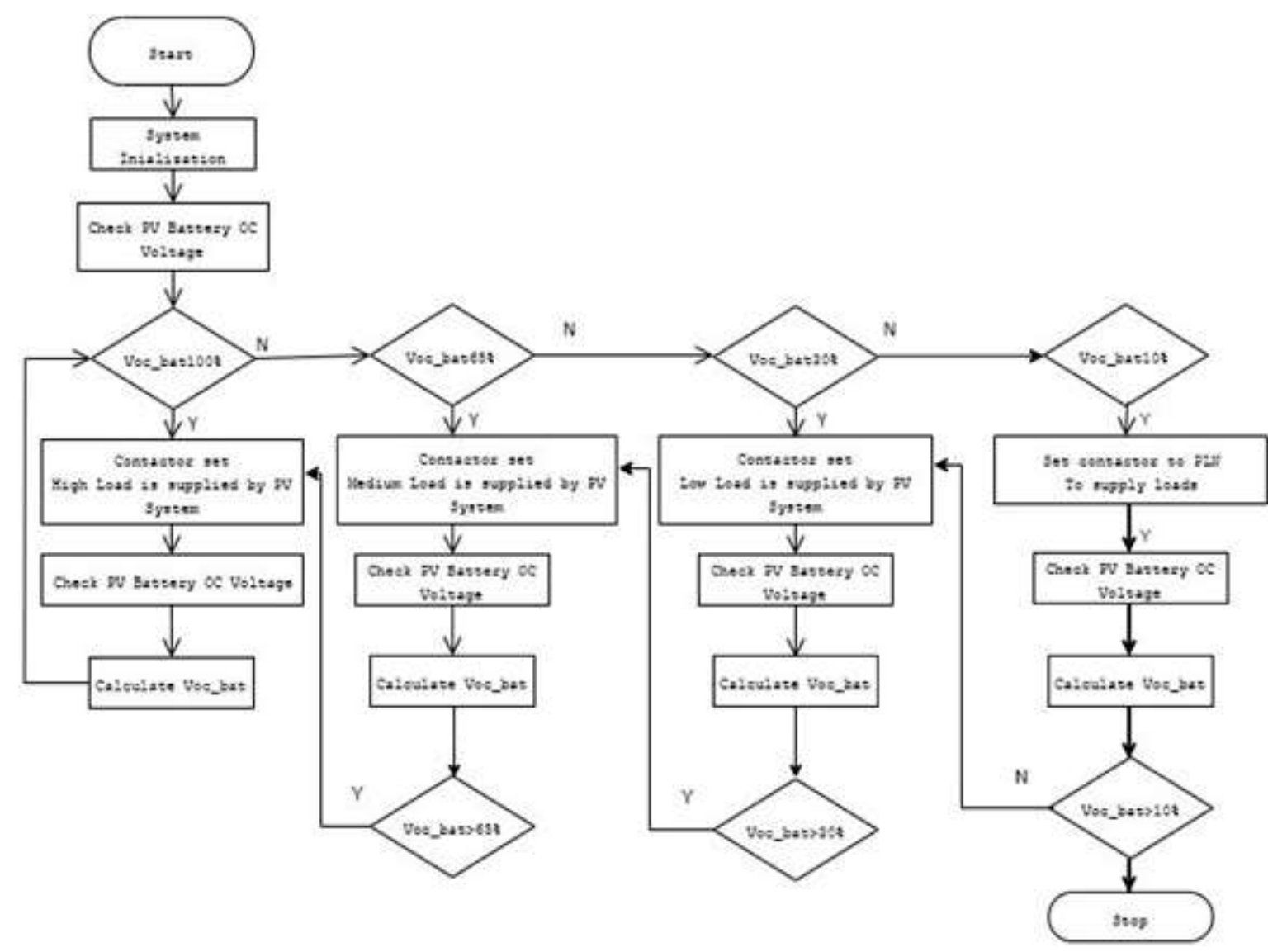

Figure 5. LMS mechanism designed

This system works continuously checking the battery capacity, weather $100 \%, 65 \%$, and $30 \%$ to be able to determine the status of loading and supply. This condition was also influenced by charging current during the daytime. The indicator that the battery can also be charged while serving an adjusted type of load. Same as the previous research [25] for automatic transfer switch (ATS) testing on several types of loads, there is no load interruption during LMS operation to changer power supply. The main purpose of this system have been achieved. The charging conditions need to be considered for practical applications because there is no charging voltage from the PV panel during night operations. 


\section{CONCLUSION}

The management system for loading solar power plants has been designed to keep up with sunny, cloudy, or rainy weather conditions at night, taking into account the remaining capacity of a usable battery. Battery charging current and remaining battery capacity is parameter control systems that function to move the relay as a load breaker or vice versa. During daytime and sunny weather conditions, the charging current of solar panels is large enough to be able to serve high loads while simultaneously charging batteries optimally, but if the weather is cloudy and rainy conditions are also parameters of load switching. At night or in rainy weather conditions, there is no battery charging current. The remaining battery capacity is a reference for the switch to work automatically, at the time of battery voltage. The Solar Power Plant is less than $65 \%$, the switch will be transferred to the medium load, and when the battery capacity is less than $30 \%$, the switch will switch to a low load. Therefore the available Solar Power Plant capacity follows the ability when charging solar panels to be able to service the load for each cycle without stopping. PLN supply is only used as a backup when the remaining battery capacity is less than $10 \%$ to anticipate PLN outages.

\section{ACKNOWLEDGEMENTS}

The authors gratefully acknowledge the assistance rendered by DRPM KemRistek/BRIN for the financial support under Tesis Magister Research Grant 2020 (Contract No. 034/SP2H/LT/DRPM/2020).

\section{REFERENCES}

[1] Sunaryo and D. Nurachman, "Propulsion system analysis for solar-powered electric water recreational," in E3S Web of Conferences, pp. 1-7, 2018.

[2] Syafii and R. Nazir, "Performance and energy saving analysis of grid connected photovoltaic in West Sumatera," Int. J. Power Electron. Drive Syst., vol. 7, no. 4, 2016.

[3] Indonesia_Gov_Reg_No.79_2014, “Tetang: (http://www.den.go.id/upload/ken/ppken.pdf).” 2014

Kebijakan Energi Nasional,

2014 ,

[4] T. R. Ayodele, A. S. O. Ogunjuyigbe, K. O. Akpeji, and O. O. Akinola, "Prioritized rule based load management technique for residential building powered by PV/battery system," Eng. Sci. Technol. an Int. J., 2017.

[5] M. Mirzaei and M. Z. Mohiabadi, "Comparative analysis of energy yield of different tracking modes of PV systems in semiarid climate conditions: The case of Iran," Renew. Energy, vol. 119, pp. 00-409, 2018.

[6] M. R. N. Chinmay K.N., Kumari K, "Economical management of microgrid for optimal participation in electricity market," J. Energy Storage, vol. 21, pp. 657-664, February 2019.

[7] S. Ghazali, R. Putra, and H. Putra, "Online monitoring of grid connected residential photovoltaic system using zigbee and web server," Indones. J. Electr. Eng. Comput. Sci., vol. 7, no. 3, pp. 668-675, 2017.

[8] Syafii, R. Nazir, Kamshory, and M. Hadi, "Improve dual axis solar tracker algorithm based on sunrise and sunset position," J. Electr. Syst., vol. 11, no. 4, 2015.

[9] J. Ahmed and Z. Salam, "A Modified P\&O Maximum Power Point Tracking Method With Reduced Steady-State Oscillation and Improved Tracking Efficiency," IEEE Trans. Sustain. Energy, vol. 7, no. 4, pp. 1506-1515, 2016.

[10] H. A. Kazem, Renewable and Sustainable Energy, Principles and Applications",. LAP LAMBERT Academic Publishing, 2013.

[11] D. M. M. S. Sopian K, Elbreki A.M , Ruslan M.H., Ali Najah Al-Shamani, Elhub B., Azher M. Abed, Husam Abdulrasool Hasan, "A stand-alone Photovoltaic System Design and Sizing: a Greenhouse Application in Sabha City: Case study in Libya," in The 3rd Engineering Science And Technology Vol. 3, International Conference (ESTIC), 2016.

[12] Y. J. Campana P. E., Wästhage L., Nookuea W., Tan Y., "Optimization and assessment of floating and floatingtracking PV systems integrated in on- and off-grid hybrid energy systems,” Sol. Energy, vol. 177, pp. 782-795, 2019.

[13] M. L. R. Rajeswari and C. V. K. Bhanu, "Design of Stand-Alone Photovoltaic System - A Case Study," Int. J. Eng. Res. Appl., vol. 3, no. 2, pp. 510-515, 2013.

[14] S. R. Salkuti, "Optimal operation management of grid-connected microgrids under uncertainty," Indones. J. Electr. Eng. Comput. Sci., vol. 16, no. 3, pp. 1163-1170, 2019.

[15] R. Nazir, K. Kanada, Syafii, and P. Coveria, "Optimization active and reactive power flow for PV connected to grid system using Newton Raphson method," in Energy Procedia, vol. 68, 2015.

[16] T. Khengwee, P. R. P. Hoole, K. Pirapaharan, A. M. A. Haidar, and S. R. H. Hoole, "A review of sarawak off-grid renewable energy potential and challenges," J. Telecommun. Electron. Comput. Eng., vol. 9, no. 3-10, pp. 29-33, 2017.

[17] I. N. S. Kumara, T. Urmee, Y. Divayana, I. . Setiawan, A. A. G. . Pawitra, and A. Jaya, "Implementation of Gridconnected PV Plant in Remote Location in Sumbawa Island of Indonesia: Lesson Learned," in International Conference on Smart Green Technology in Electrical and Information Systems, ICSGTEIS 2018, pp. 203-209, 2018.

[18] Syafii, Zaini, D. Juliandri, and Wati, "Design and Economic Analysis of Grid-Connected Photovoltaic on Electrical Engineering Building in Universitas Andalas," Int. J. Eng. Technol., vol. 10, no. 4, pp. 1093-1101, 2018.

[19] H. Yang, G. Zheng, C. Lou, D. An, and J. Burnett, "Grid-connected building-integrated photovoltaics: A Hong Kong case study," Sol. Energy, 2004.

[20] L. Olatomiwa, "Optimal configuration assessments of hybrid renewable power supply for rural healthcare facilities,"

Design of arduino-based loading management system to improve continuity of solar power... (Muhardika) 
Energy Reports, vol. 2, pp. 141-146, 2016.

[21] A. Haghighat Mamaghani, S. A. Avella Escandon, B. Najafi, A. Shirazi, and F. Rinaldi, "Techno-economic feasibility of photovoltaic, wind, diesel and hybrid electrification systems for off-grid rural electrification in Colombia," Renew. Energy, vol. 97, pp. 293-305, 2016.

[22] N. Yimen, O. Hamandjoda, L. Meva'a, B. Ndzana, and J. Nganhou, "Analyzing of a photovoltaic/wind/biogas/pumped-hydro off-grid hybrid system for rural electrification in Sub-Saharan Africa - Case study of Djoundé in Northern Cameroon," Energies, vol. 11, no. 10, 2018.

[23] S. Hybrid, "Inverter Luminous 1500VA," 2019. [Online]. Available: https://luminous.co.id/inverter/solar-hybrid/.

[24] Kepmen-ESDM-No.1567 K/21/MEM/2018, "Rencana Usaha Penyediaan Tenaga Listrik 2017,” PT.PLN (Persero) Tahun 2018-2027, 2018.

[25] Syafii, S. A. Putri, and Y. Mayura, "Improve continuity supply of pv system using arduino-based transfer switch," Int. J. Sci. Technol. Res., vol. 9, no. 2, pp. 768-772, 2020.

\section{BIOGRAPHIES OF AUTHORS}
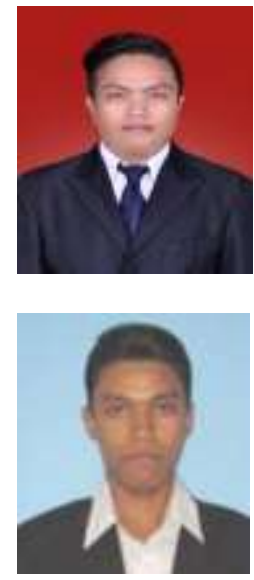

Muhardika received a Bachelor of Applied Science degree in electrical engineering from Padang State University in 2015. He is currently a Postgraduate Student in Electrical Engineering, Andalas University, Indonesia. His research interests are new and renewable energy, smart grids.

Syafii received a B.Sc degree in electrical engineering from the University of North Sumatera, in 1997 and M.T. degree in electrical engineering from Bandung Institute of Technology, Indonesia, in 2002 and a Ph.D. degree from Universiti Teknologi Malaysia in 2011. He is currently a senior lecturer in the Dept. of Electrical Engineering, Universitas Andalas, Indonesia. His research interests are new and renewable energy, smart grid and power system computation 